were under eighteen years of age and 11,843 were nineteen or more. Of the full-time students, 35,723 out of 47,793 men and 11,528 out of 15,275 women in England were receiving assistance by way of scholarships, exhibitions or other awards from public or private funds; for Wales the corresponding figures are 2,726 out of 3,187 men and 1,166 out of 1,307 women; and for Scotland, 6,331 out of 10,315 men and 2,089 out of 3,828 women. Of the 61,295 full-time men students, $36 \cdot 1$ per cent were in arts, $22 \cdot 3$ per cent in pure science, $16 \cdot 6$ per cent in medicine and 17.0 per cent in technology; for the 20,410 women students the corresponding figures are $63 \cdot 7,18 \cdot 0,14 \cdot 4$ and 0.7 per cent, respectively. Medicine and dentistry claimed 52.2 per cent of the part-time advanced students, arts 34.9 per cent, pure science $9 \cdot 2$ per cent and technology $2 \cdot 7$ per cent, compared with $49 \cdot 6,35 \cdot 6,9 \cdot 3$ and $4 \cdot 8$ per cent, respectively, during 1953-54.

The recurrent income of the universities and university colleges of Great Britain increased by $£ 4,488,054$ to $£ 35,600,078$, of which $£ 25,059,434$ was from parliamentary grants, $£ 3,815,306$ from fees, $£ 1,448,212$ from endowments, $£ 1,140,643$ from local authority grants and $£ 401,379$ from donations and subscriptions. Of the total income of $£ 26,200,007$ from public funds and $£ 9,400,001$ from other sources, the University of London received $£ 7,803,937$ and

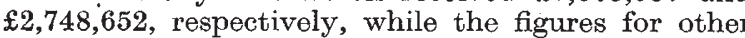
universities were Cambridge $£ 1,659,067$ and $£ 1,371,494$; Oxford, $£ 1,489,853$ and $£ 780,791$; Manchester, £1,293,893 and £321,976; Leeds, $£ 1,107,057$ and $£ 350,586$; Birmingham, $£ 1,069,933$ and $£ 438,788$; Durham, $£ 1,152,240$ and $£ 369,320$; Liverpool, $£ 1,057,395$ and $£ 320,826$; Bristol, $£ 825,567$ and $£ 430,386$; Sheffield, $£ 710,398$ and $£ 186,487$; Nottingham, $£ 568,488$ and $£ 148,410$; and Reading, $£ 624,686$ and $£ 93,438$. No other English university or university college had an income exceeding half a million pounds; but for the four universities in Scotland the incomes from public funds and from other sources were Aberdeen, $£ 576,117$ and $£ 138,690$; Edinburgh, $£ 1,235,533$ and $£ 415,402$; Glasgow, £1,229,990 and £397,244 ; and St. Andrews $£ 612,090$ and $£ 129,357$. The University of Wales, including the Welsh National School of Medicine, received $£ 1,326,200$ and $£ 336,405$.

Of the recurrent expenditure of $£ 34,791,656$, an increase of 15 per cent on 1953-54, administration accounted for 7.2 per cent, departmental maintenance $69 \cdot 3$ per cent, maintenance of premises $12 \cdot 0$ per cent, and miscellaneous expenditure $10 \cdot 2$ per cent. Departmental maintenance, which includes salaries of teaching staff, payments for superannuation, the running costs of laboratories, lecture rooms, libraries and museums, and the supply of books, specimens, materials, apparatus, etc., increased by $£ 2,095,004$ to $£ 24,100,985$ and expenditure on maintenance of buildings increased by 8.2 per cent. Salaries and superannuation amounted to $£ 15,958,695$, compared with $£ 13,616,426$ in $1953-54$, the increase being $17 \cdot 2$ per cent for teaching staff and 14.8 per cent for technicians and laboratory assistants.

Library expenditure, excluding general maintenance of library buildings, rates, heat, light, repairs, etc., amounted to $£ 1,352,244$, or $3 \cdot 8$ per cent of the total expenditure, compared with 4.0 per cent in 1953-54 and $3 \cdot 9$ per cent in 1952-53. Of this total, $£ 707,236$ was for salaries and wages, $£ 154,963$ on periodicals and $£ 101,885$ on bindings. Of the $£ 310,102$ expended on books, $£ 72,939$ was in the schools and colleges of the University of London, including $£ 12,192$ at the Central Library, $£ 6,183$ at the London School of Economies, $£ 9,273$ at University College, $£ 5,153$ at the School of Oriental and African Studies and $£ 4,909$ at Bedford College. The University of Oxford spent $£ 31,585$ on books ; Cambridge, $£ 22,796$; Manchester, £21,559 ; Liverpool, £11,608; Leeds, $£ 10,116$; Durham, $£ 12,993$; Birmingham, $£ 10,215$; and Bristol, $£ 9,553$. Only the Universities of London $(£ 44,813)$, Oxford $(£ 14,948)$ and Cambridge $(£ 12,233)$ spent more than $£ 10,000$ on periodicals, and only

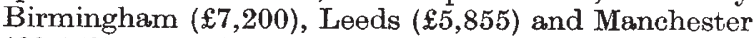
$(£ 6,458)$ more than $£ 5,000$. The University of Wales spent $£ 14,789$ on books and $£ 8,457$ on periodicals. In Scotland, Edinburgh spent $£ 15,087$ on books and $£ 6,813$ on periodicals ; Glasgow, $£ 11,662$ and $£ 7,382$; St. Andrews, $£ 11,856$ and $£ 4,702$; and Aberdeen, $£ 8,333$ and $£ 3,954$.

\section{INSTITUTE OF PHYSICS REPORT FOR 1955}

$T$ HE thirty-sixth annual report of the Board of the Institute of Physics*, which was presented to the annual meeting of the Institute in London on July 16, indicates the growing importance of the work of the Institute and the increasing number of physicists now being employed in industry, teaching and research. The total membership rose during the year under reviow by 397 to 5,146 , reaching the five thousand mark for the first time. There were increases in all the grades of membership, with substantial increases in the associateship and graduateship grades. 726 applications for election or transfer to the various grades were received during the year, compared with 579 during 1954. Eleven of the fifty-four candidates who took the examination for graduateship of the Institute were successful. The numbers of candidates for the final examinations for the National Certificate in Applied Physics were 309 for the ordinary level and $\mathbf{8 2}$ for the higher, compared with 206 and 75, respectively, in 1954.

The report mentions that representatives of the membership committee visited seven technical colleges which had applied for official recognition, or extension of recognition, by the Board as institutions suitable for training of physicists in accordance with the Institute's membership regulations. The degrees of the University of Malaya were also recognized by the Board. The report of an inquiry by the Board into the availability of places for students of physics in the universities and larger technical colleges of Great Britain was published by the Institute in its September Bulletin, and reprints have since been widely circulated. Many requests continue to be received from those leaving school and others concerning careers in physics, and the deputy secretary of the Institute, Mr. N. Clarke; has addressed meetings on this subject in Aberdeen, Bristol, Edinburgh, Ewell, Glasgow and Swansea. The Institute has kept in close and constant touch with the permanent officers of the American Institute of Physics and has made a joint inquiry with the Physical Society, London, about the likely demand for English translations of Russian papers on pure and applied physics.

* Thirty-sixth Annual Report of the Board of the Institute of Physics, 1955. Pp. 18. (London: Institute of Physics; 1956.) 
The need for a recognized permanent body in Great Britain before which papers on the application of nuclear energy and ancillary subjects could be read and discussed was the subject of negotiations initiated by the major engineering institutions, and as a result a body known as the British Nuclear Energy Conference was formally inaugurated at a meeting in London on November 30. The Institute of Physics and the Institutions of Civil, Mechanical, Electrical and Chemical Engineers are the founding constituent bodies, and each has three representatives on the governing board.

Details of the various activities of the nine branches and seven specialist subject groups of the Institute are briefly referred to in the report. There are eight local branches in Great Britain, and also an autonom ous Australian Branch, under the presidency of Prof. L. G. H. Huxley, with divisions in the different States. During November 22-24 an exhibition of scientific instruments and apparatus was held by the Australian Branch and was well attended. The Liverpool and North Wales Branch held its inaugural meeting on May 19, 1955, in the Department of Electrical Engineering of the University of Liverpool, and the inaugural lecture was delivered by Prof. $Z$. Kopal, professor of astronomy in the University of Manchester, who took as his subject "The Physics of the Sun" (published in Brit. J. App. Phys., 7, 119 ; April 1956). The Scottish Branch, in addition to holding meetings in Glasgow, Edinburgh, Aberdeen and Dundee, arranged a course of five lectures on computers, and a conference on the training of physicists for industry was held by the Yorkshire Branch at the Rotherham Technical College on April 21. The two main subjects for discussion at the annual conference of the Education Group during April 14-15 were the teaching of thermodynamics and the place of physies in a liberal education; the Electronics Group held a symposium on recent developments in magnetic materials, and the X-ray Analysis Group has continued its work, under the direction of Prof: A. J. C. Wilson (University College, Cardiff), on the provision of data for the index of diffraction patterns which is published by the American Society for Testing Materials.

Both the circulation and the advertisement revenue of the Institute's two monthly periodicals, the Journal of Scientific Instruments and the British Journal of Applied Physics, increased satisfactorily during the year ; unfortunately, costs of production continued to rise. The amount of material submitted and published in 1955 was similar to that in 1954 ; but as more papers were published than accepted, the average delay between submission and publication of acceptable manuscripts was reduced slightly. The fourth supplement to the British Journal of Applied Physics, containing the proceedings of the Electronics Group's symposium held in Cambridge, 1954, on luminescence with particular reference to inorganic phosphors, was published as part of the 1955 volume. The twelve monthly issues of the Institute's Bulletin (issued to members only) contained fourteen articles, some of them invited contributions and others based on lectures given to the Education Group. The Bulletin is appearing in a new and improved form this year. In the "Physics in Industry" series, two new volumes-. "X-ray Diffraction by Polycrystalline Materials" containing contributions by thirty-one members of the X-ray Analysis Group, and "Physics of Fibres" by H. J. Woods-were published during the year, and three booklets in the "Student Monograph" series were issued.

At the general meeting of the Institute the following were elected to take office on October 1 : President, Mr. O. W. Humphreys; Vice-President, Dr. B. P. Dudding; Honorary Treasurer, Dr. J. Taylor ; Honorary Secretary, Prof. F. A. Vick; New Ordinary Members of the Board, Dr. L. R. G. Treloar and Mr. G. W. Warren. Sir George Thomson, master of Corpus Christi College, Cambridge, was elected to honorary fellowship in recognition of his outstanding contributions to physics and his services to physicists.

\section{HIGH CLOUD OVER SOUTHERN ENGLAND}

A SUBSIDIARY task of the Air Ministry Meteorological Research Flight is the making of observations of cirrus clouds, the white ice-crystal clouds, called popularly 'mare's tails' in one form, which are the highest clouds ordinarily visible. The rarely seen mother-of-pearl and noctilucent clouds are much higher. R. J. Murgatroyd, chief meteorological officer of the Flight, discusses these observa. tions in Professional Note 119 of the Meteorological Office*.

Cirrus clouds are not easily studied in flying through them, because often they are so tenuous that the observer finds it hard to tell when he has reached a cirrus cloud clearly seen from far below. The tops, however, are more sharply defined than the bases. It was found that cirrus cloud is almost always entirely within the troposphere, though the tops are often only just below the tropopause. On a few occasions reported in the note, 'cloud' was seen in the stratosphere; but it is known that the observations in July and August 1953, which constitute the majority, were actually of volcanic dust produced by an eruption in Alaska on July 7. The heights of the tops were usually within $2,000 \mathrm{ft}$. of the tropopause, and the lower the tropopause the closer the cirrus tops were to it. Cirrus, which looks so thin from the ground, is usually between 3,000 and $5,000 \mathrm{ft}$. thick, and may be as much as $12,000 \mathrm{ft}$. thick.

An important feature when cirrus clouds were visible was a moist layer extending downwind from them at the same level, which became more pronounced (depression of frost point below dry bulb decreasing) as the clouds were approached. The humidity in the clouds seems to be surprisingly low. The depression of the frost point ranged from 12 to -2 deg. F., with a mean depression of about $3 \mathrm{deg}$. F. This average value corresponds to about 80 per cent relative humidity with respect to ice and, since the saturation vapour pressure is higher over water than ice, a markedly lower one (50 per cent) with respect to water, which is remarkable if it is correct that saturation with respect to water is necessary for the formation of cirrus cloud. The presence or absence of cirrus is a useful guide to the fighter pilot as to whether his aircraft is likely to produce a marked condensation trail, as it was found that, when cirrus was present, the probability of making a very persistent condensation trail was roughly about twelve times ( 60 per cent of flights) the probability (only 5 per cent of flights) when it was not.

* Air Ministry : Meteorological Office. Professional Note No. 119 : High Cloud over Southern England. By R. J. Murgatroyd and P. Gold
snith. Pp. 20. (M.0. 524 S.) (London : H.M.S.O., 1956.) 9d. net. 